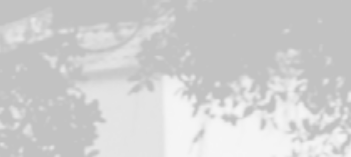

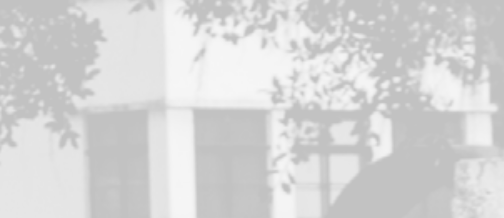

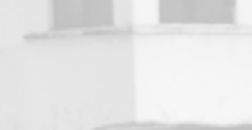

$-1,5$
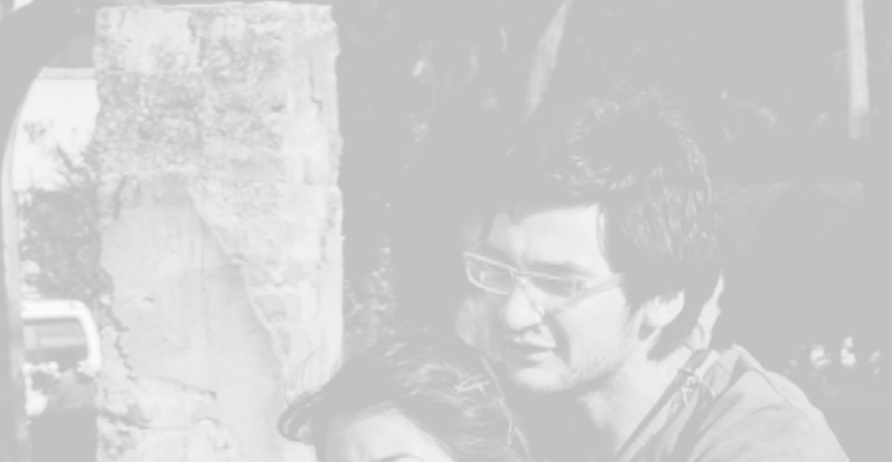

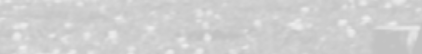
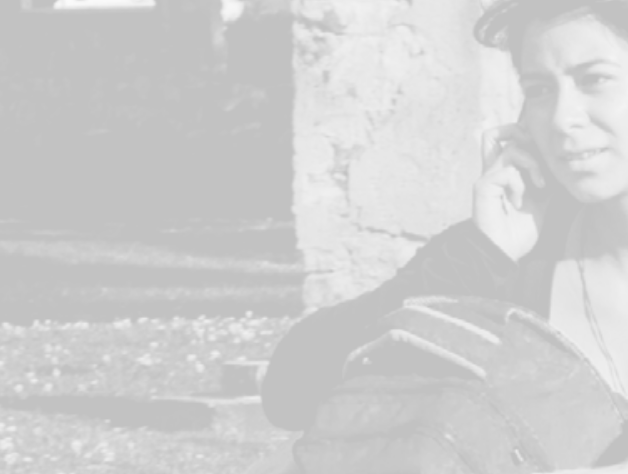

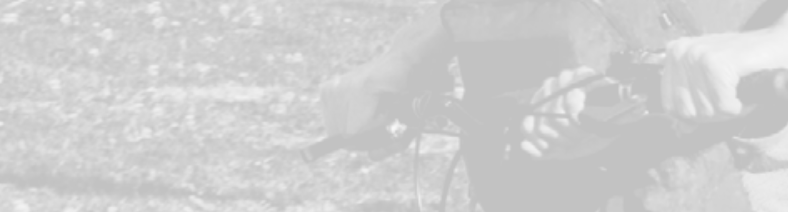
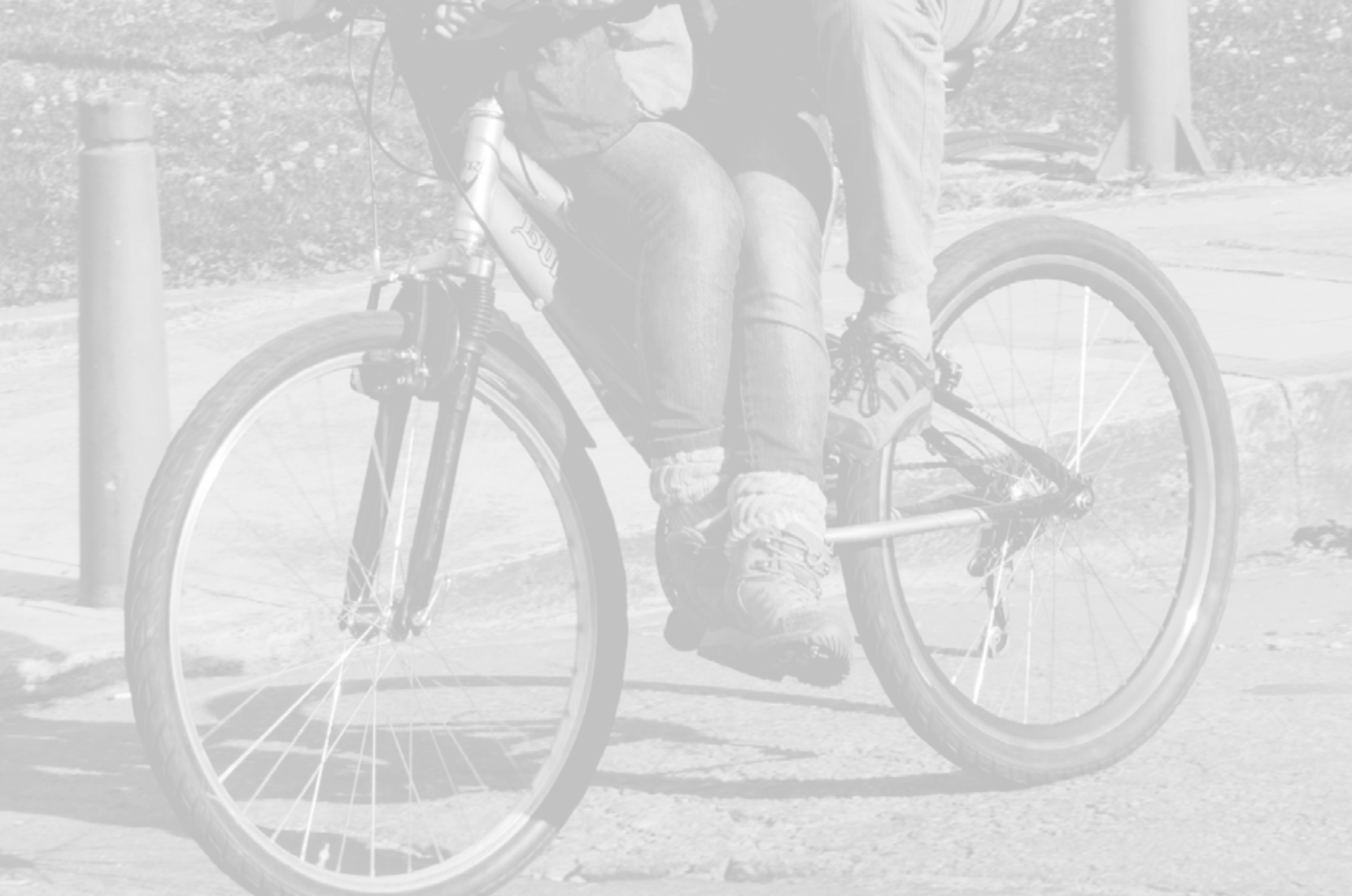


\title{
La educación universitaria en Venezuela 2013-2019. Aproximación desde el trabajo que se hace en la base de datos de la Línea de Investigación Memoria Educativa Venezolana
}

\author{
LUIS BRAVO JÁUREGUI \\ Licenciado en Educación por la Escuela de Educación (UCV). Doctor en Ciencias del \\ Desarrollo, Centro de Estudios del Desarrollo (CENDES). Coordinador e investigador \\ responsable de la Línea de Investigación Memoria Educativa Venezolana adscrita al Centro \\ de Investigaciones de la Escuela de Educación.
}

\section{Ramón Uzcátegui Pacheco}

Licenciado en Educación de la Escuela de Educación y doctor en Humanidades de la Facultad de Humanidades y Educación (UCV). Excoordinador e Investigador responsable de la LIMEV.

Resumen

El artículo busca caracterizar la educación universitaria en el período 2013-2019, con especial atención al desempeño de sus indicadores más básicos en perspectivas pedagógica y constitucional.

El marco procedimental y conceptual que orienta el trabajo hecho en la Línea de Investigación Memoria Educativa Venezolana se maneja con frecuencia para dar seguimiento al acontecer educativo del país. Con ello se llega a la conclusión sumaria de que enormes distancias separan los resultados arrojados por el discurso oficial de lo dictado en la Constitución, lo cual se evidencia al compararlos con las lecturas que se hacen del desarrollo de la Universidad.

Palabras clave

Educación universitaria, universidad, constitución, seguimiento, matrícula, financiamiento, planes de desarrollo. 


\title{
University education in Venezuela during 2013-2019: An approach from the database work about the Educational Ve- nezuelan Memory research
}

\begin{abstract}
The objective of this article is to characterize Venezuelan university education in the 2013-2019 period with attention to the performance of its basic indicators, in a pedagogic and constitutional perspective. Procedural and conceptual framework are intensively managed, which guide the research about the Educational Venezuelan Memory, to track the educational events of the country. The conclusion is that there are large gaps between what Constitution and the official speech declare, and between this latter and the results of the university development's review, according to the bureaucracy of the centralized administration.
\end{abstract}

Key words

University education, University, Constitution, Tracking, Enrollment, Financing, Development plans.

\section{O ensino superior na Venezuela 2013-2019.}

Aproximação ao trabalho que se faz na base de dados da linha de pesquisa Memória Educacional Venezuelana

\section{LUIS BRAVO JÁUREGUI}

\section{Sumário}

O artigo procura caracterizar o ensino superior no período 2013-2019 prestando atenção especial no desempenho dos indicadores mais básicos da perspectiva pedagógica e constitucional.

O quadro processual e conceitual que orienta o trabalho feito na linha de pesquisa Memória Educacional Venezuelana é tratado frequentamente para acompanhar os eventos educacionais do país. Com isso é possível a conclusão sumária das grandes distâncias que dividem os resultados do discurso oficial do declarado na Constituição, o que é evidente na comparação das leituras feitas sobre o desenvolvimento da Universidade, conforme relatado pelo próprio funcionário da administração centralizada.

\section{Palavras-chave}

Ensino superior, Universidade, Constituição, acompanhamento, matrícula, financiamento, planos de desenvolvimento. 


\section{Presentación}

Esta es una aproximación a la dinámica fundamental de la universidad desde el trabajo que hacemos en la Línea de Investigación Memoria Educativa Venezolana $^{1}$, a partir de un conjunto de esquemas, cuadros y gráficos brevemente comentados, que expresan lo que estimamos como los grandes asuntos asociados al tipo de desarrollo que tiene la universidad venezolana, en un período histórico profundamente marcado por la incertidumbre respecto al futuro del país y su educación.

Se busca caracterizar el estado de la educación universitaria en el período de enero de 2013 a agosto de 2019, en atención a las definiciones que hace la Constitución de 1999, priorizando aquellas relacionadas con la creación de instituciones, la dinámica matricular y el tipo de financiamiento que se produce. Esto no solo servirá para identificar las diferencias y similitudes, sino también para resaltar el abismo entre lo que dice la Constitución vigente y la realidad mostrada por los esquemas y cuadros sobre el conjunto de instituciones que hoy, en el discurso educativo oficial, tienen el nombre de Universidad. Los contrastes se harán entre lo que puede ser resaltado como elemental de la Constitución de 1999 y lo que dice la información procesada en esta investigación, sirva para lo cual el siguiente esquema indicativo de lo fundamental del marco normativo respecto a la Universidad, como lo indica el contrato social que tenemos los venezolanos: 
La Constitución, sus prescripciones para la Educación, la Ciencia y la Tecnología son (deberían ser) el marco referencial (lógico-formal) primario para entender el acuerdo político y social alrededor del asunto Universidad en la Venezuela que se conforma desde 1999

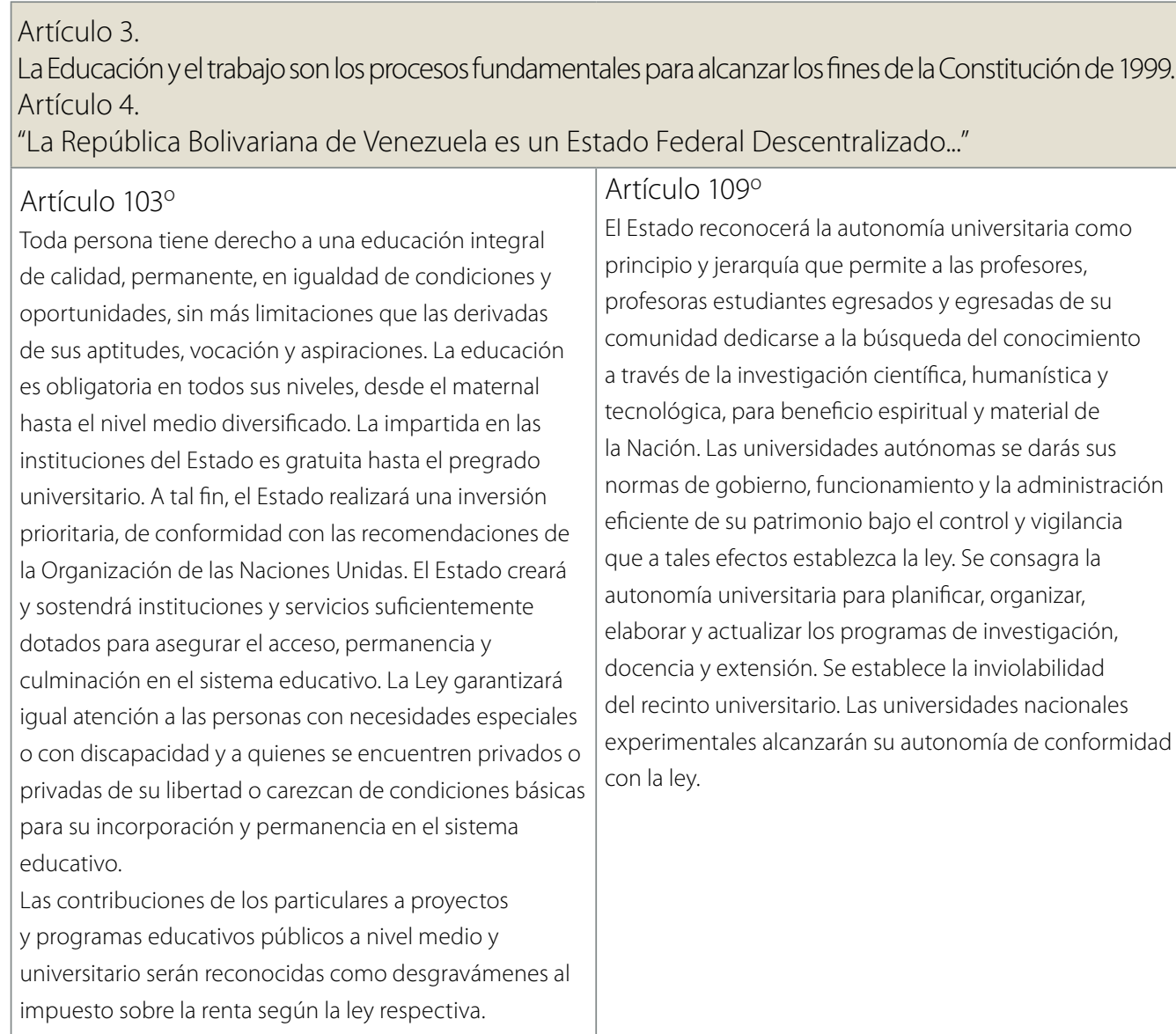

Fuente: Asamblea Nacional constituyente (1999) Constitución de la República Bolivariana de Venezuela. Publicada en Gaceta Oficial No. 5,908 extraordinario, de fecha 19 de febrero de 2009. Ediciones de la Asamblea Nacional impreso en la Imprenta Nacinal y Gaceta Oficial. http://wwwminci.gob.ve/wp-content/ uploads/2011/04/CONSTITUCION.pdf

Con las comparaciones señaladas se busca orientar el análisis de lo que cambia a partir de 2013, cuando arriba una versión del Proyecto Bolivariano que perdió a su protagonista más emblemático y, a pesar de ello, subsiste dentro de una depresión generalizada que la amenaza severamente; se expondrá la labor del equipo: procesar y generar información académicamente sustentada respecto al acontecer universitario, a partir del conjunto de ideas y realidades sintetizadas en este esquema del Sistema Educativo Escolar Venezolano vigente, que ojalá sirva para situar con alguna claridad metodológica lo que se afirma y los medios para hacerlo: 


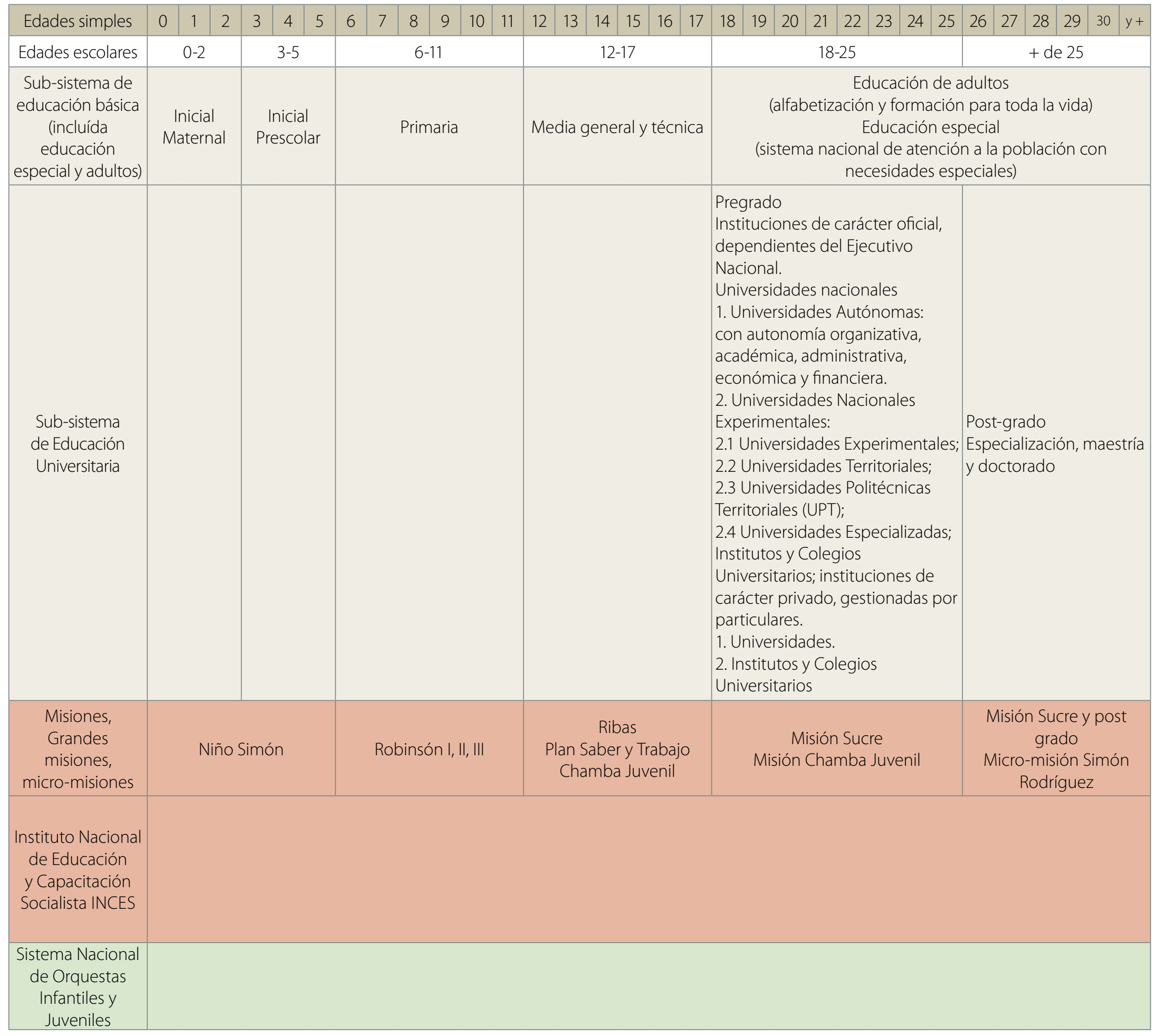
Universidades $\mid$ núm. 83, enero-marzo $2020 \mid$ UDUAL $\mid$ DOI: https://doi.org/10.36888/udual.universidades.2020.83.97 97
La educación universitaria en Venezuela 201-2019. Aproximación desde el trabajo que se hace en $\mid$ Luis Bravo Jáuregui y Ramón Uzcátegui Pacheco 97 la base de datos de la Línea de Investigación Memoria Educativa Venezolana 


\section{Lagestión y política realentrelos deseos plasmados en la Constitución de 1999 y los requerimientos de sobrevivencia de una hegemonía}

El discurso presidencial a la nación de este año 2019 indica con claridad la hoja de ruta que quisiera transitar el Gobierno Central en cuanto a la educación. Sin considerar otros aspectos notables de esta exposición, se puede afirmar que en la acuciosa reseña que hizo Daniel Arias (2019) resalta la importancia que se le otorga al Plan País como orientador de la política pública y la reiteración por lograr 100 por ciento de cobertura del sistema educativo escolar, cuando las propias informaciones de Miraflores respecto a los indicadores principales de escolaridad señalan con claridad lo que es poco más que una quimera:

Cadena Nacional de Radio y Televisión.

Entrega de Memoria y Cuenta 2018, Plan de la Patria 20192025 y anuncios de ajustes económicos puntuales.

Discurso expresado por Nicolás Maduro:

25- Anunció la meta de $100 \%$ de cobertura educativa nacional de primaria a universidad.

[...] 27- Señaló sus éxitos educativos con una matrícula creciente de estudiantes.

28- Señaló la creación de 11 nuevas universidades en 2018.

29- Señaló el éxito de los planes de alimentación escolar, atendiendo 5.3 millones de estudiantes.

30- Recordó la entrega de 4 millones de kit escolares de morrales y uniformes.

31- Anunció el morral bolivariano familiar con la obra de Karl Marx, conocida como El Capital.

32- Citó a la UNESCO como referencia del éxito educativo del Gobierno Nacional a nivel mundial.

38- Entregó el Plan de la Patria 2019-2025. (Arias Alfonzo, 2019)

43- Recordó el éxito del Sistema Nacional de Orquestas.

44- Señaló que José Ignacio Abreu, fundador del Sistema Nacional Orquesta, lo quería mucho en lo personal hasta su muerte.

Por un lado, están los deseos del presidente; por otro, los requerimientos de supervivencia del régimen instalado en 1999 y pretendidamente remozado bajo la idea de Estado Comunal, en el 2013, para canalizar todas sus energías en la construcción del socialismo de corte bolivariano y chavista. Incluso, una cosa dice la Constitución y otra muy distinta, la gestión pública efectiva desarrollada desde 1999, particular- 
mente la del 2003, cuando desde la perspectiva particular desaparece la legislación vigente como guía de opción de la gestión pública, para hacer del Plan de la Patria (Galaviz, 2019A) la inspiración cuasi divina de la gestión pública oficial en materia de educación universitaria.

La infraestructura normativa asociada a la universidad venezolana va más allá de la Constitución ${ }^{2}$, pero ocurre que la Ley Orgánica de Educación (2009) y la reglamentación interna de las universidades tienen una falla de origen: fueron diseñadas para disfrutar de una ilimitada expansión del gasto público y un Gobierno sin términos para sustentar con financiamiento constante y sonante la voluntad de poder de su liderazgo más conspicuo.

En el año 2013 se instala un modo de conducción de la educación universitaria que exagera el ya desmesurado discurso inclusivo, acentúa la concentración del poder en el Ministerio y sube los decibeles a la ya alta propensión a convertir la educación universitaria en objeto de propaganda oficial de tipo marcadamente sectario, en términos administrativos. Se declara el mantenimiento del modelo general establecido desde 1999, pero parece haber ocurrido un cambio en la definición de la política, correspondiente a la que señala Ruth Galaviz (2019A, p. 10), cuando se intenta proporcionar más peso a la gestión pública centralmente planificada y se sustituye definitivamente la Constitución por el segundo Plan de la Patria (2013-2019), principalmente su objetivo 1.5:

[...] Consolidar un estilo científico, tecnológico e innovador de carácter transformador, diverso, creativo y dinámico, garante de la independencia y la soberanía económica, contribuyendo así a la construcción del Modelo Productivo Socialista, el fortalecimiento de la Ética Socialista y la satisfacción efectiva de las necesidades del pueblo venezolano.

9. Industria innovación e infraestructura

[...] Objetivo 1.5.2

Fortalecer los espacios y programas de formación para el trabajo liberador, fomentando los valores patrióticos y el sentido crítico (CONATEL, 2013).

Esto llego al punto en que el recién nombrado ministro del Poder Popular para la Educación Universitaria propuso, a mediados de 2019, un Plan General de Rectificación, Cambio y Renovación del Ministerio del Poder Popular para la Educación Universitaria $^{3}$ que se resume de la siguiente manera, en cuanto direccionalidad formal soldada al Plan de la Patria (Galaviz, 1999A): 


\begin{tabular}{|c|c|}
\hline Objetivo estratégico: & $\begin{array}{l}\text { Alinear la política de educación universitaria, que permita el } \\
\text { cumplimiento del Plan de la Patria 2019-2025, la recuperación } \\
\text { económica, el crecimiento y la prosperidad de la República } \\
\text { Bolivariana de Venezuela en el contexto de la Rectificación, } \\
\text { Cambios y Renovación rumbo al socialismo bolivariano. }\end{array}$ \\
\hline $\begin{array}{l}\text { Objetivos de Rectificación } \\
\text { de los procesos llevados } \\
\text { en el sector universitario }\end{array}$ & $\begin{array}{l}\text { 1. Visibilizar los logros de la Revolución en nuestras universidades } \\
\text { y sistema de educación universitario bolivariano. } \\
\text { 2. Fortalecer un poderoso movimiento universitario que } \\
\text { garantice espacios ganados y avance en la conquista de más } \\
\text { espacios universitarios. } \\
\text { 3. Formar profesionales que organicen su destino laboral y } \\
\text { productivo. }\end{array}$ \\
\hline $\begin{array}{l}\text { Objetivos de Cambios } \\
\text { en los modos de atención } \\
\text { y organización de las tareas }\end{array}$ & $\begin{array}{l}\text { 1. Orientar la calidad universitaria de Venezuela hacia la } \\
\text { pertinencia de la educación para el desarrollo de la nación } \\
\text { con pre y post grado, y líneas de investigación, alineados con } \\
\text { los Motores Productivos de la Agenda Económica Bolivariana. } \\
\text { 2. Desarrollar incubadoras productivas universitarias para el } \\
\text { socialismo, en cada universidad perteneciente a la Asociación de } \\
\text { Rectores Bolivarianos. } \\
\text { 3. Autofinanciar la educación universitaria a través de la venta de } \\
\text { programas de educación a distancia, productos de investigación } \\
\text { y desarrollo científico y sistema de empresas universitarias. }\end{array}$ \\
\hline $\begin{array}{l}\text { Objetivos de Renovación } \\
\text { de los métodos de } \\
\text { gobierno }\end{array}$ & $\begin{array}{l}\text { 1. Consolidar una comunidad universitaria alineada } \\
\text { solidariamente a la Rectificación, Cambios y Renovación para la } \\
\text { productividad socialista de la educación universitaria. } \\
\text { 2. Potencializar el talento humano revolucionario, dispuesto a } \\
\text { construir lo nuevo para el socialismo bolivariano. }\end{array}$ \\
\hline
\end{tabular}

Después de analizar el significado del resumen expuesto, se concluye que la educación universitaria no se conduce por las vías que pautan la Constitución y la legislación vigente, sino todo lo contrario: se mueve a contracorriente de la función educativa que supone un Estado federal descentralizado; define una política de territorialización que puede interpretarse como reparto arbitrario por el país de la formación centralmente planteada (Miraflores); fomenta la hipercentralización, más que respeto a la autonomía de las instituciones y la regionalización supuesta en 1999; la centralización renovada en los hechos, se manifiesta al expropiar la facultad de definir las carreras en cada una de las instituciones, para imponer los Planes Nacionales de Formación (PNF), que uniforman tajantemente las carreras a todo lo largo y ancho del país universitario. Esto informa cotidianamente Ruth Galaviz en su blog ${ }^{4}$, cuando habla de las acciones realizadas para concretar la territorialización ensayada desde el arranque de la Misión Alma Mater: 
Programas Nacionales de Formación (PNF). 2008: correspondientes al nivel de pregrado, serían administrados en todo el territorio nacional, vinculándose durante todo el proceso formativo con las comunidades y el ejercicio profesional, a partir de las necesidades y características de las localidades. Hasta la fecha se han creado 78 PNF en diferentes áreas de conocimiento. (Galaviz, 2019A, p. 1)

La anterior información merecería más atención de la que se le presta en este momento, cuando es imperioso avanzar en las realidades que muestra el discurso oficial respecto a la configuración institucional creada para implantar los dos últimos planes de la patria ${ }^{5}$ y proyectar un tercero. En consecuencia, tal y como se hace evidente en el cuadro 1, la realidad es que la búsqueda por la autonomía universitaria en 1999 se perdió radicalmente a partir de 2013, cuando la distribución porcentual de los tipos de institución denuncia haber relegado a la universidad autónoma, quedando apenas 5 reconocidas por el Gobierno Central frente al 7\% del total de instituciones universitarias:

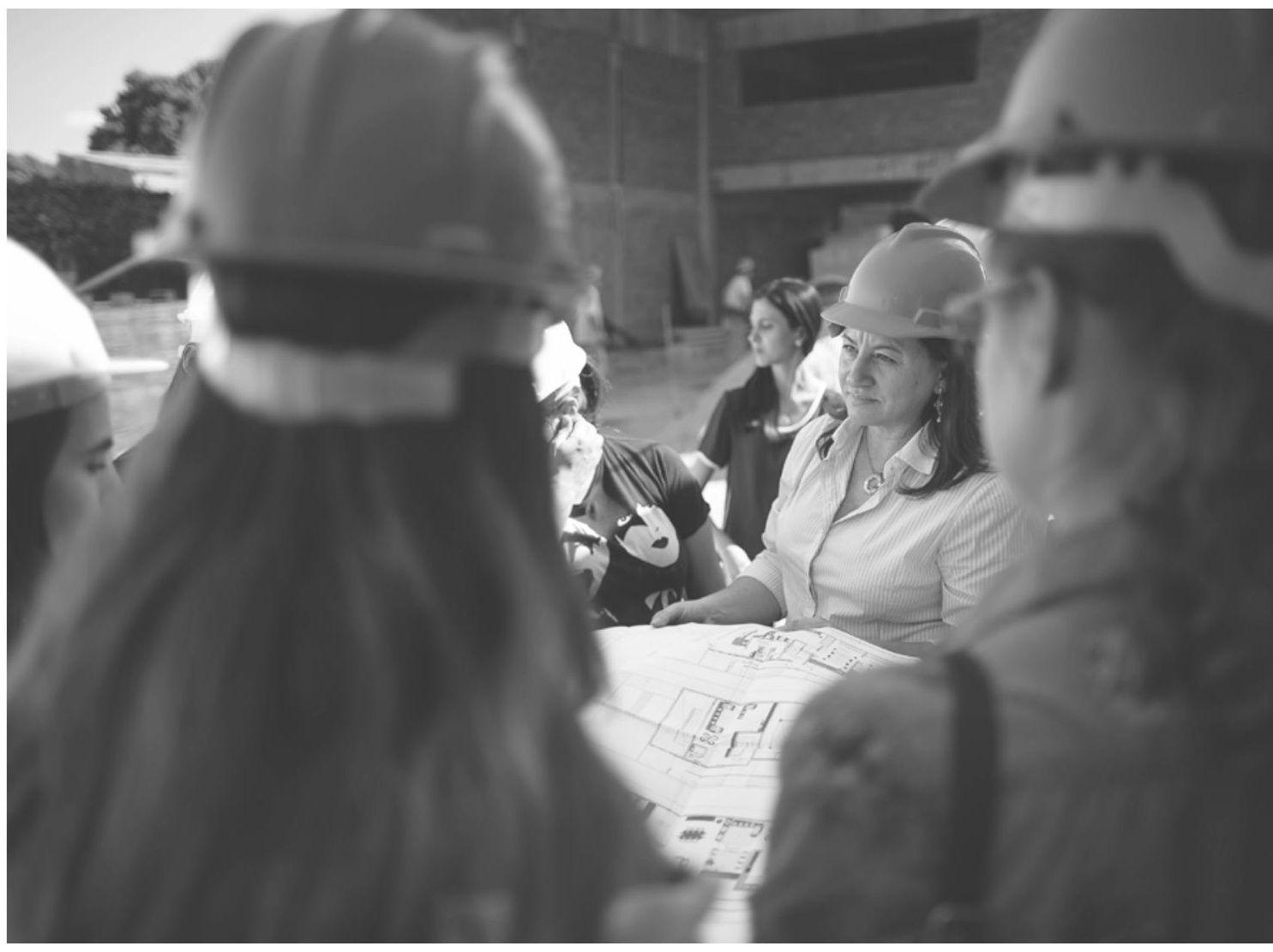




\section{Cuadro 1}

\begin{tabular}{|c|c|c|c|}
\hline Tipo de institución al 2019 & $\mathrm{~N}$ & $\%$ Parcial & $\%$ Total \\
\hline $\begin{array}{l}1 \text { Instituciones de carácter oficial, } \\
\text { dependientes del Ejecutivo Nacional. }\end{array}$ & 72 & $100 \%$ & $44 \%$ \\
\hline $\begin{array}{l}\text { 1.1 Universidades autónomas: con autonomía } \\
\text { organizativa, académica, administrativa, } \\
\text { económica y financiera. }\end{array}$ & 5 & $7 \%$ & \\
\hline $\begin{array}{l}\text { 1.2 Universidades Experimentales: creadas } \\
\text { con el fin de ensayar nuevas orientaciones } \\
\text { y estructuras de educación superior }{ }^{*} \text {, gozan } \\
\text { de autonomía dentro de las condiciones de } \\
\text { su naturaleza experimental. }\end{array}$ & 27 & $38 \%$ & \\
\hline $\begin{array}{l}\text { 1.2.1 Universidades Territoriales: en } \\
\text { estrecha relación con "[...] las producción } \\
\text { y necesidades productivas, sociales } \\
\text { y culturales de espacios territoriales } \\
\text { determinados (ciudades, estados, distritos } \\
\text { funcionales, provincias federales)"** con el } \\
\text { fin de democratizar el acceso al SEU y servir } \\
\text { de elemento dinamizador del desarrollo } \\
\text { endógeno. }\end{array}$ & 2 & $3 \%$ & \\
\hline $\begin{array}{l}\text { 1.2.2 Universidades Politécnicas Territoriales } \\
\text { (UPT): abarcan múltiples campos de } \\
\text { estudio y abordan las necesidades de } \\
\text { su contexto territorial “[...] a partir de las } \\
\text { realidades geohistóricas, culturales, sociales } \\
\text { y productivas"***, para así conformar una } \\
\text { nueva geopolítica nacional. }\end{array}$ & 26 & $36 \%$ & \\
\hline $\begin{array}{l}\text { 1.2.3 Universidades Especializadas: } \\
\text { destinadas al desarrollo de las fortalezas } \\
\text { en determinadas áreas de conocimiento } \\
\text { para la conformación de "[...] comunidades } \\
\text { de investigación y apropiación social del } \\
\text { conocimiento"*** constituyendo redes } \\
\text { nacionales en conexión con las demás IEU. }\end{array}$ & 7 & $10 \%$ & \\
\hline $\begin{array}{l}1.3 \text { Institutos y colegios Universitarios: } \\
\text { destinados a "...) proveer recursos humanos } \\
\text { en el campo de la ciencia, la tecnología y } \\
\text { de los servicios que se requieran para el } \\
\text { desarrollo del país y de la región" }{ }^{\prime * * * *} \text {. }\end{array}$ & 5 & $7 \%$ & \\
\hline $\begin{array}{l}2 \text { Instituciones de carácter privado, } \\
\text { gestionadas por particulares. }\end{array}$ & 93 & 100 & $56 \%$ \\
\hline 2.1 Universidades. & 25 & $27 \%$ & \\
\hline 2.2 Institutos Universitarios. & 59 & $63 \%$ & \\
\hline 2.3 Colegios Universitarios. & 9 & $10 \%$ & \\
\hline
\end{tabular}

Fuente: Ruth Galaviz (2019). Temas de educación universitaria https://temaseducacionuniversitria.blogspot.com/2019/08/el-sistema-de-educacion-universitaria.html agosto 03, 2019. Consultado el 29-08-2019.

102 Universidades $\mid$ núm. 83, enero-marzo 2020| UDUAL | DOI: https://doi.org/10.36888/udual.universidades.2020.83.97 Luis Bravo Jáuregui y Ramón Uzcátegui Pacheco $\mid$ La educación universitaria en Venezuela 201-2019. Aproximación desde el trabajo que se hace en la base de datos de la Línea de Investigación Memoria Educativa Venezolana 
Si bien lo anterior no es por completo producto de los cambios ocurridos en 2013, sí lo es del discurso que lo acompaña, pues definitivamente, y como nunca antes, el Plan de la Patria sustituye a la Constitución y a los resquicios del ideal democrático que existían en la discursividad educativa del presidente Chávez. Se exhibe como un logro lo que debería ser una falla vergonzosa de gestión pública.

Población matriculada en el sistema educativo escolar y el peso diferencial del subsistema universitario

La pretensión de atender la educación continua y continuada por las mayorías suele ser norma y principio, que une las más disímiles formas de administrar el campo educativo, en buena parte de las sociedades preocupadas por la ascensión de sus ciudadanos. Sobre todo si esa aspiración se asume dentro de un clima político de inclusión democrática. Venezuela no es la excepción, especialmente porque a partir de 1999 la hegemonía en el seno del Estado dio paso a un proyecto político excluyente, con una oferta electoral que ponía el foco en la inclusión de los amplios sectores olvidados por las administraciones anteriores y en revertir la supuesta privatización de la educación, que avanzaba. Sin embargo, a partir de 2013, es más prioridad que la inclusión educativa (entrada libre, masiva y gratuita a la Universidad), la pretendida contribución de la universidad a la Construcción del Socialismo Bolivariano y Chavista, según se lee en el Plan de la Patria 2013-2019 (2013, p.1) que calza mucho más con el tipo de institucionalidad visualizada en el siguiente cuadro, hecho para representar la forma en que se expresa hoy la universidad venezolana*. 
Cuadro 2 Modelo representativo de la estructura básica del sub-sistema de educación universitaria al 2019.

Construido con base en las prescripciones de la Ley e universidades vigentes, LOE y en lo concerniente a la tipología de instituciones de educación universitaria que utiliza:

Galaviz Ruth (2019) El Sistema de Educación Universitaria Venezolano de cara al Plan de la Patria.

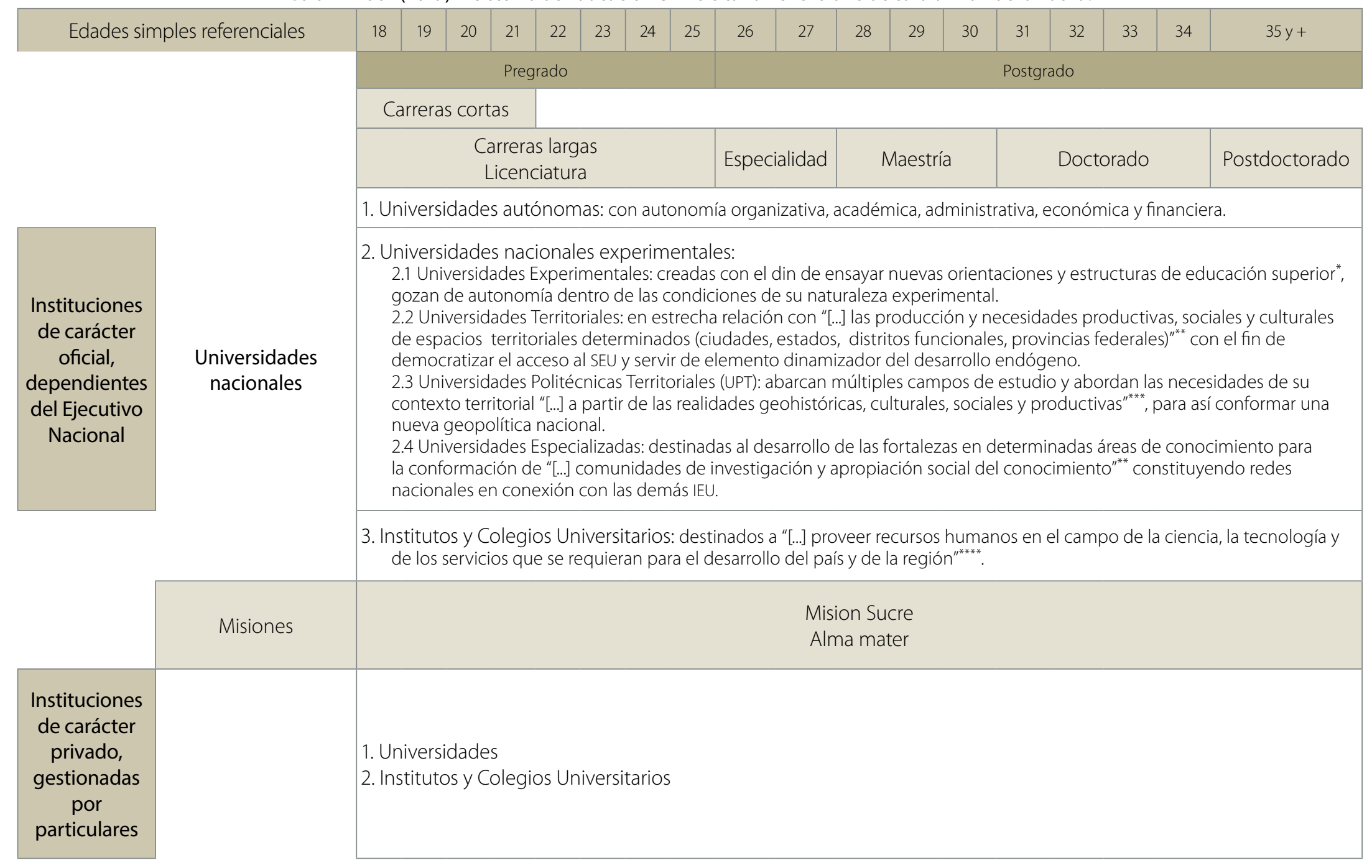


El subsistema debería crecer armónicamente con la posibilidad de incluir a la población en la edad correspondiente en la universidad dibujada en el 109, pero la realidad que se visualiza en el cuadro 2 es que prolifera una institucionalidad más proclive a la sintonía con las necesidades materiales y espirituales de la pervivencia de la hegemonía en el poder fáctico de la nación.

En la Línea de Investigación Memoria Educativa Venezolana nos ocupamos, entre otras cosas, de construir una representación longitudinal (diacrónica) de la dinámica de los dos subsistemas educativos que configuran el Sistema Educativo Escolar Venezolano. Con ese fin publicamos todos los años un informe anual que se dispone a consideración del público como servicio de información de la Universidad Central de Venezuela prestado por nuestra LIMEV, el cual se pone a consideración del público por BOX en la siguiente dirección: https://app.box.com/s/ fxyc616uoqteti0ifca69id3rk06sic5.

Con estos informes fijamos la mirada en el desarrollo de dos variables asociadas al comportamiento central del Sistema Educativo Escolar Venezolano: la población matriculada en alguno de su subsistemas, niveles y modalidades; y el financiamiento, estimado a partir de la información oficial disponible sobre cómo en Venezuela se gasta e invierte en educación, en general, y particularmente y en la universitaria.

A continuación, se puede observar qué dice la relación Población total respecto a Matrícula total, sumatoria de los dos subsistemas (universitario y el básico), en cuanto a la evolución y capacidad inclusiva de la gestión pública de la educación: si avanza, se estanca o retrocede como indicador del estado de la variable escolaridad, gracias a una serie que permite pulsar con información oficial, pública y de larga trayectoria, las grandes tendencias históricas de la capacidad inclusiva del Sistema Escolar Venezolano, desde una perspectiva académica, pedagógica y constitucional.

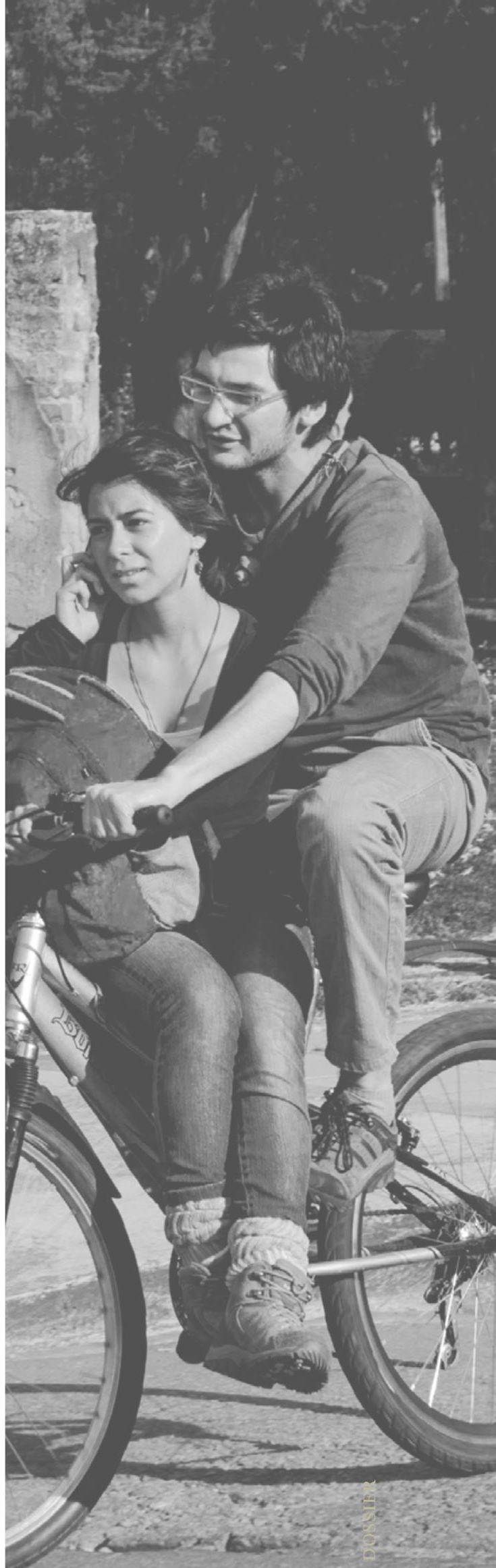


Cuadro 3. Población incluida (estimada por inscripción año fiscal) en el Sistema Educativo-Escolar Venezolano 1958-2018

\begin{tabular}{|c|c|c|c|c|c|}
\hline Año fiscal & $\begin{array}{c}\text { Matrícula } \\
\text { Total }\end{array}$ & Variación \% & $\begin{array}{c}\text { Población } \\
\text { total }\end{array}$ & Variación \% & $\begin{array}{l}\text { \% matrícula } \\
\text { respecto a } \\
\text { población }\end{array}$ \\
\hline 1998 & $7,008,692$ & $3.2 \%$ & $23,242,435$ & $2.0 \%$ & $30.2 \%$ \\
\hline 1999 & $7,029,477$ & $0.3 \%$ & $23,706,711$ & $2.0 \%$ & $29.7 \%$ \\
\hline 2000 & $7,303,155$ & $3.9 \%$ & $24,169,744$ & $2.0 \%$ & $30.2 \%$ \\
\hline 2001 & $7,814,371$ & $7.0 \%$ & $24,631,900$ & $1.9 \%$ & $31.7 \%$ \\
\hline 2002 & $8,253,735$ & $5.6 \%$ & $25,093,337$ & $1.9 \%$ & $32.9 \%$ \\
\hline 2003 & $10,651,645$ & $29.1 \%$ & $25,553,504$ & $1.8 \%$ & $41.7 \%$ \\
\hline 2004 & $12,950,267$ & $21.6 \%$ & $26,127,351$ & 2.25 & $49.6 \%$ \\
\hline 2005 & $13,690,841$ & $5.7 \%$ & $26,577,423$ & 1.75 & $51.5 \%$ \\
\hline 2006 & $13,954,105$ & $1.9 \%$ & $27,030,136$ & $1.7 \%$ & $51.6 \%$ \\
\hline 2007 & $11,281,506$ & $-19.2 \%$ & $27,483,208$ & $1.7 \%$ & $41.0 \%$ \\
\hline 2008 & $11,209,325$ & $-0.6 \%$ & $27,934,783$ & 1.65 & $40.1 \%$ \\
\hline 2009 & $10,639,590$ & $-5.1 \%$ & $28,384,132$ & $1.6 \%$ & $37.5 \%$ \\
\hline 2010 & $10,693,529$ & $0.5 \%$ & $28,833,845$ & $1.6 \%$ & $37.1 \%$ \\
\hline 2011 & $10,861,752$ & $1.6 \%$ & $28,946,101$ & $1.4 \%$ & $37.5 \%$ \\
\hline 2012 & $10,971,482$ & $0.10 \%$ & $29,601,112$ & $1.1 \%$ & $37.7 \%$ \\
\hline 2013 & $10,794,091$ & $-1.6 \%$ & $30,110,365$ & $1.7 \%$ & $35.8 \%$ \\
\hline 2014 & $10,664,924$ & $-1.2 \%$ & $30,620,404$ & $1.7 \%$ & $34.8 \%$ \\
\hline 2015 & $10,662,641$ & $-0.01 \%$ & $30,620,404$ & $0 \%$ & $35.0 \%$ \\
\hline 2016 & $10,541,845$ & $-1.0 \%$ & $31,028,637$ & $1.0 \%$ & $33.9 \%$ \\
\hline 2017 & $13,045,335$ & $23.7 \%$ & $31,828,110$ & $1.1 \%$ & $33.9 \%$ \\
\hline 2018 & $10,494,869$ & $-19.5 \%$ & $31,828,110$ & $0.0 \%$ & $32.9 \%$ \\
\hline 2019 & $10,494,869$ & $0 \%$ & $32,219,521$ & $1.2 \%$ & $32.5 \%$ \\
\hline
\end{tabular}

Fuentes y notas. Matrícula 1958-2015. Sumatoria Educación Básica y Superior desde el Cuadro N1 de la sección de estadísticas del Ministerio del Poder Popular para la Educación (o equivalente en el tiempo) y los boletines OPSU y la introducción del ministro a las Memorias y Cuenta del Ministerio de Universidad o equivalentes. En adelante (2016) se utiliza un promedio de lo que informa el Presidente de la República en su informe a la nación todos los eneros, según se registran en: https://app.box.com/s/bgw0vrbvf2eb1dp2qlxvbz8i8oqfba9q. Del 2003 en adelante incluye misiones educativas. Población 1958-2019. INE (o equivalente) en su página web, consultada todos los años www.ine.gov.ve/

106 Universidades $\mid$ núm. 83, enero-marzo 2020 | UDUAL $\mid$ DOI: https://doi.org/10.36888/udual.universidades.2020.83.97

Luis Bravo Jáuregui y Ramón Uzcátegui Pacheco La educación universitaria en Venezuela 201-2019. Aproximación desde el trabajo que se hace en la base de datos de la Línea de Investigación Memoria Educativa Venezolana 
Gráfico 1

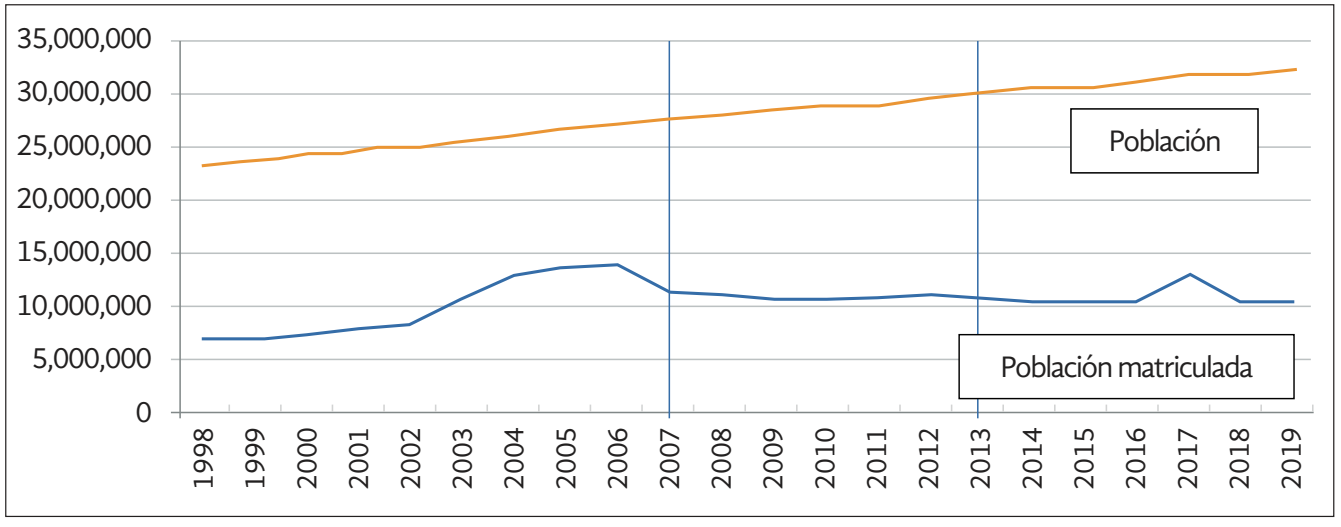

Es notoriamente visible en el cuadro y su gráfico que desde el 2007 estamos dentro de un ciclo de estancamiento y retroceso de la escolaridad, que a partir del 2013 se hace recesivo y depresivo, en tanto se mantienen los preocupantes y sostenidos signos de disminución del servicio educativo escolar, sin que el Estado, vía Ministerios (actores principales), muestren preocupación y ocupación alguna, más allá de una que otra referencia marginal a la necesidad de relanzar el aparato escolar como se hace patente en el anexo al informe anual $2019^{* *}$, en el que se produce una síntesis de la información oficial en la comunicación pública.

Contrasta el pobre desempeño de la educación primaria y media con el espectacular crecimiento diferencial de la universidad, respecto a los otros niveles del sistema educativo escolar, como se visualiza en el siguiente cuadro estadístico: 
Cuadro 4. Distribución educación básica y educación universitaria

\begin{tabular}{|c|c|c|c|c|c|c|c|c|c|}
\hline Años & $\begin{array}{c}\text { Total } \\
\text { como } \\
\text { sumatoria }\end{array}$ & Inicial N & $\begin{array}{l}\text { Inicial \% } \\
\text { del total }\end{array}$ & $\begin{array}{c}\text { Primaria } \\
\mathrm{N}\end{array}$ & $\begin{array}{c}\text { Primaria } \\
\% \text { de } \\
\text { total }\end{array}$ & $\begin{array}{c}\text { Media } \\
\text { general y } \\
\text { técnica N }\end{array}$ & $\begin{array}{c}\text { Media \% } \\
\text { de total }\end{array}$ & $\begin{array}{c}\text { Educación } \\
\text { Universitaria } \\
\mathrm{N}\end{array}$ & $\begin{array}{c}\text { Universidad } \\
\%\end{array}$ \\
\hline 1998-99 & $4,940,161$ & 882,468 & $17.9 \%$ & $3,261,343$ & $66.0 \%$ & & $0.0 \%$ & 796,350 & $16.1 \%$ \\
\hline 1999-00 & $4,942,828$ & 896,593 & $18.1 \%$ & $3,227,797$ & $65.3 \%$ & & $0.0 \%$ & 818,438 & $16.6 \%$ \\
\hline 2000-01 & $5,190,679$ & 914,349 & $17.6 \%$ & $3,423,480$ & $66.0 \%$ & & $0.0 \%$ & 852,850 & $16.4 \%$ \\
\hline 2001-02 & $5,336,835$ & 948,554 & $17.8 \%$ & $3,506,780$ & $65.7 \%$ & & $0.0 \%$ & 881,501 & $16.5 \%$ \\
\hline 2002-03 & $5,651,463$ & 946,761 & $16.8 \%$ & $3,443,847$ & $60.9 \%$ & & $0.0 \%$ & $1,260,855$ & $22.3 \%$ \\
\hline 2003-04 & $5,838,690$ & $1,266,048$ & $21.7 \%$ & $3,449,579$ & $59.1 \%$ & & $0.0 \%$ & $1,123,063$ & $19.2 \%$ \\
\hline 2004-05 & $8,068,838$ & $1,343,446$ & $16.6 \%$ & $3,449,290$ & $42.7 \%$ & $2,028,388$ & $25.1 \%$ & $1,247,714$ & $15.5 \%$ \\
\hline 2005-06 & $8,719,414$ & $1,355,373$ & $15.5 \%$ & $3,452,062$ & $39.6 \%$ & $2,104,857$ & $24.1 \%$ & $1,807,122$ & $20.7 \%$ \\
\hline 2006-07 & $9,256,335$ & $1,425,431$ & $15.4 \%$ & $3,521,139$ & $38.0 \%$ & $2,174,619$ & $23.5 \%$ & $2,135,146$ & $23.1 \%$ \\
\hline 2007-08 & $9,241,444$ & $1,443,031$ & $15.6 \%$ & $3,439,199$ & $37.2 \%$ & $2,224,214$ & $24.1 \%$ & $2,135,000$ & $23.1 \%$ \\
\hline 2008-09 & $9,420,372$ & $1,535,359$ & $16.3 \%$ & $3,432,592$ & $36.4 \%$ & $2,252,421$ & $23.9 \%$ & $2,200,000$ & $23.4 \%$ \\
\hline 2009-10 & $9,446,414$ & $1,563,117$ & $16.5 \%$ & $3,428,361$ & $36.3 \%$ & $2,254,936$ & $23.9 \%$ & $2,200,000$ & $23.3 \%$ \\
\hline 2010-11 & $9,579,493$ & $1,516,472$ & $15.8 \%$ & $3,435,421$ & $35.9 \%$ & $2,287,393$ & $23.9 \%$ & $2,340,207$ & $24.4 \%$ \\
\hline $2011-12$ & $9,813,319$ & $1,503,541$ & $15.3 \%$ & $3,452,070$ & $35.2 \%$ & $2,354,412$ & $24.0 \%$ & $2,503,296$ & $25.5 \%$ \\
\hline $2012-13$ & $10,051,375$ & $1,605,391$ & $16.0 \%$ & $3,473,886$ & $34.6 \%$ & $2,372,098$ & $23.6 \%$ & $2,600,000$ & $25.9 \%$ \\
\hline 2013-14 & $9,987,667$ & $1,560,585$ & $15.6 \%$ & $3,467,714$ & $34.7 \%$ & $2,339,355$ & $23.4 \%$ & $2,620,013$ & $26.2 \%$ \\
\hline 2014-15 & $9,970,968$ & $1,597,541$ & $16.0 \%$ & $3,449,592$ & $34.6 \%$ & $2,301,822$ & $23.1 \%$ & $2,622,013$ & $26.3 \%$ \\
\hline 2015-16 & $9,876,996$ & $1,605,391$ & $16.3 \%$ & $3,449,592$ & $34.9 \%$ & $2,200,000$ & $22.3 \%$ & $2,622,013$ & $26.5 \%$ \\
\hline 2016-17 & $9,573,037$ & $1,442,301$ & $15.1 \%$ & $3,264,726$ & $34.1 \%$ & $2,243,997$ & $23.4 \%$ & $2,622,013$ & 27.45 \\
\hline 2017-18 & $10,365,792$ & $1,796,709$ & $17.3 \%$ & $3,314,822$ & $32.0 \%$ & $2,254,261$ & $21.7 \%$ & $3,000,000$ & $29.0 \%$ \\
\hline 2018-19 & $9,458,024$ & $1,575,714$ & $16.7 \%$ & $2,869,310$ & $30.3 \%$ & $2,163,000$ & $22.9 \%$ & $2,850,000$ & $30.1 \%$ \\
\hline
\end{tabular}

Fuente: 1998-2015. Ministerio de educación universitaria (o equivalente en el tiempo), Memorias y Cuenta anuales. Resúmenes estadísticos, cuadro 1.1 (o equivalente).

2016-18. Ministerio del Poder Popular para la Educación. Memorias y Cuenta. Versión informal recibida por correo electrónico de fuente privada.

08 Universidades $\mid$ núm. 83, enero-marzo 2020 | UDUAL $\mid$ DOI: https://doi.org/10.36888/udual.universidades.2020.83.97

Luis Bravo Jáuregui y Ramón Uzcátegui Pacheco $\mid$ La educación universitaria en Venezuela 201-2019. Aproximación desde el trabajo que se hace en la base de datos de la Línea de Investigación Memoria Educativa Venezolana 
Gráfico 2. Inscripción oficial en el año escolar 2018-2019 (cuentas principales)

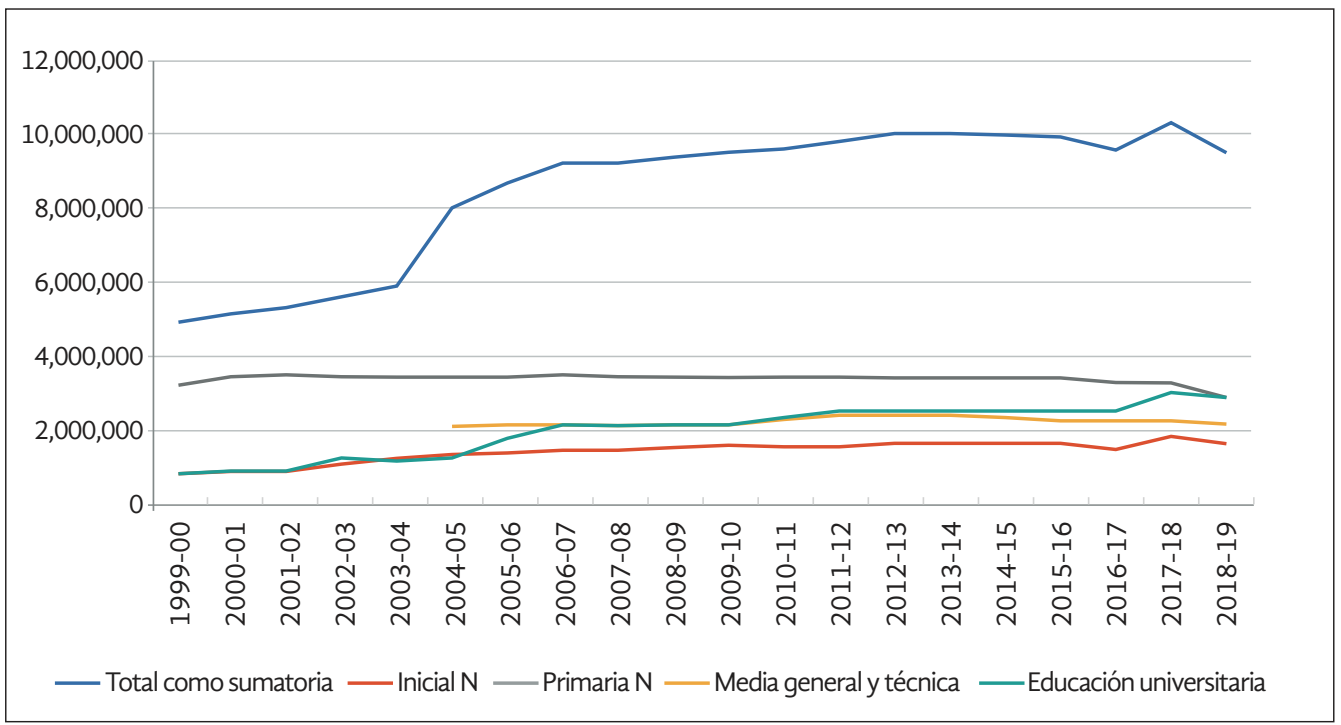

El próximo lunes 17 de septiembre inicia el año escolar 2018-2019 con la apertura de 24 mil 411 instituciones educativas oficiales y 5.001 planteles privados que recibirán a 7 millones 664 mil 869 estudiantes de educación inicial y primaria.

[...] Reiteró que en el inicio del año escolar asistirán 6 millones 442 mil 296 estudiantes a escuelas públicas y 1 millón 202 mil 573 a instituciones privadas.

Istúriz detalló que de los 6 millones 442 mil 296 de estudiantes de la educación pública, 1 millón 575 mil 714 se encuentran inscritos en educación inicial; 2 millones 869 mil 310 en primaria; 1 millón 651 mil en educación media; 135 mil 512 Educación Técnica; 171 mil 643 en la modalidad de educación de adultos y adultas, y 39 mil 117 en la modalidad de educación especial.

Prensa MPPE/ Fotos: Archivo Caracas. http://www.me.gob.ve/index.php/noticias/94-noticias-2029/enero-3/3867-estudiantes-colmaron-de-alegria-las-aulas-venezolanas-durante-el-regreso-a-clases 08.01 .2018

Después de leer el cuadro anterior poca duda puede restar de que la prioridad real de la gestión pública ha sido la universidad, al menos hasta el 2013, cuando pasa del $16 \%$ de total de la matrícula a $31.1 \%$ al hacer un análisis de extremos.

\section{Los cambios suscitados en 2013 actuaron en sentido contrario al crecimiento matricular universitario, asunto prioritario desde 1999}

La universidad venezolana ha tenido un crecimiento sostenido a partir de 1958, desde 1999 a 2002 lo exhibe alto y lo enaltece aún más hasta el 2013, momento preciso que se busca caracterizar, cuando ese crecimiento se ralentiza y muestra posibles indicadores de que la expansión matricular ocurrida no es como lo vocea el discurso oficial.** 
Cuadro 5. Inscripción total en el subsistema universitario (incluye Misión Sucre e instituciones de todo tipo y nivel)

\begin{tabular}{|c|c|c|c|c|}
\hline Año Fiscal N & $\begin{array}{c}1 \\
\text { Población N }\end{array}$ & $\begin{array}{c}2 \\
\text { Inscripción total } \\
\text { Subsistema } \\
\text { Universitario N }\end{array}$ & $\begin{array}{c}3 \\
\text { Variación } \% \\
\text { interanual }\end{array}$ & $\begin{array}{c}4 \\
\% \text { Universidad } \\
\text { de la población }\end{array}$ \\
\hline 1998 & $23,242,435$ & 700,000 & & $3.0 \%$ \\
\hline 1999 & $23,706,711$ & 796,350 & $13.8 \%$ & $3.4 \%$ \\
\hline 2000 & $24,169,744$ & 818,438 & $2.8 \%$ & $3.4 \%$ \\
\hline 2001 & $24,631,900$ & 852,850 & $4.2 \%$ & $3.5 \%$ \\
\hline 2002 & $25,093,337$ & 881,501 & $3.4 \%$ & $3.5 \%$ \\
\hline 2003 & $25,553,504$ & $1,260,855$ & $43.0 \%$ & $4.9 \%$ \\
\hline 2004 & $26,127,351$ & $1,123,063$ & $-10.9 \%$ & $4.3 \%$ \\
\hline 2005 & $26,577,423$ & $1,247,714$ & $11.1 \%$ & $4.7 \%$ \\
\hline 2006 & $27,030,136$ & $1,807,122$ & $44.8 \%$ & $6.7 \%$ \\
\hline 2007 & $27,483,208$ & $2,135,146$ & $18.2 \%$ & $7.8 \%$ \\
\hline 2008 & $27,934,783$ & $2,135,000$ & $0.0 \%$ & $7.6 \%$ \\
\hline 2009 & $28,384,132$ & $2,200,000$ & $3.0 \%$ & $7.8 \%$ \\
\hline 2010 & $28,833,845$ & $2,200,000$ & $0.0 \%$ & $7.6 \%$ \\
\hline 2011 & $28,946,101$ & $2,340,207$ & $6.4 \%$ & $8.1 \%$ \\
\hline 2012 & $29,601,112$ & $2,503,296$ & $7.0 \%$ & $8.5 \%$ \\
\hline 2013 & $30,110,365$ & $2,600,000$ & $3.9 \%$ & $8.6 \%$ \\
\hline 2014 & $30,620,404$ & $2,620,013$ & $0.8 \%$ & $8.6 \%$ \\
\hline 2015 & $30,620,404$ & $2,622,013$ & $0.1 \%$ & $8.6 \%$ \\
\hline 2016 & $31,028,637$ & $2,622,013$ & $0.0 \%$ & $8.5 \%$ \\
\hline 2017 & $31,828,110$ & $3,000,000$ & $14.4 \%$ & $9.4 \%$ \\
\hline 2018 & $31,828,110$ & $2,850,000$ & $-5.0 \%$ & $9.0 \%$ \\
\hline 2019 & $32,219,521$ & $2,850,000$ & $0 \%$ & $8.8 \%$ \\
\hline
\end{tabular}

Fuentes: Años 1998-2015. Memoria y Cuenta del Ministerio de Educación Superior o equivalente (boletines de la Oficina de Planificación del sector Universitario-OPSU).

2016-2019. Memoria y Cuenta (informe a la Nación) del Presidente de la República en funciones, presentado todos los eneros.

Gráfico 3.

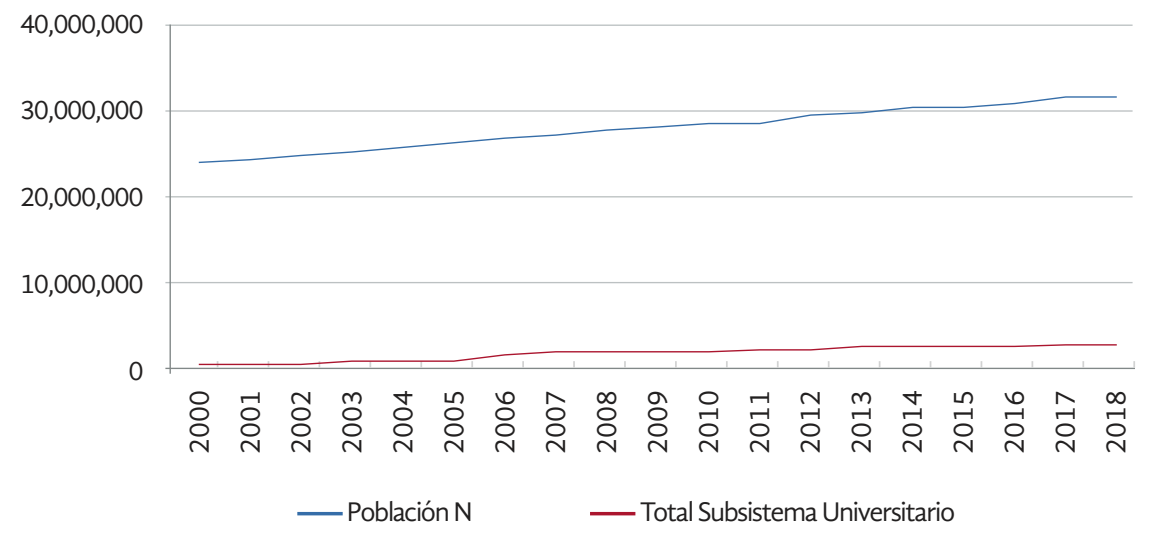

110 Universidades $\mid$ núm. 83, enero-marzo 2020 | UDUAL $\mid$ DOI: https://doi.org/10.36888/udual.universidades.2020.83.97

Luis Bravo Jáuregui y Ramón Uzcátegui Pacheco | La educación universitaria en Venezuela 201-2019. Aproximación desde el trabajo que se hace en la base de datos de la Línea de Investigación Memoria Educativa Venezolana 
La tendencia general que se puede observar en el cuadro 3, columna 2 (inscripción total en el subsistema), cuando crece entre 1999 (al inicio del proyecto político actual) y el 2019 en $257.8 \%$, nos acerca a la idea de milagro de inclusión universitaria que impuso el presidente Chávez en sus informes a la nación, como puede observarse con claridad en la Crónica Histórica (Bravo, 2019) que se produjo para describir y analizar el comportamiento de la gestión y la política pública oficial frente a la educación básica y universitaria, sobre todo en los meses de enero cuando se reseñan las memorias presidenciales presentadas ante el poder legislativo en turno o el ente que lo sustituya.

Ciertamente el examen de extremos muestra una expansión de la formación universitaria que puede calificarse de enorme, si se compara con la expansión poblacional (35.9\%), el producto interno bruto o cualquiera de los indicadores que muestran la dinámica del país entre el 1999 y 2019. Pero la realidad contable indica que, en el período concerniente a este análisis, es decir, cuando el presidente Maduro inicia sus funciones y hasta hoy, el crecimiento es notablemente más bajo, de $9.6 \%$, incluso más que el $17.2 \%$ ocurrido entre 2007 y 2012 , o el $126.9 \%$ del tramo 1999-2006. Todo ello refleja que el período 2013-2019 no está tan cerca del milagro de inclusión universitaria que declara reiteradamente el funcionariado más alto ${ }^{* * * *}$.

El profesor Robert Rodríguez (2018), en su trabajo de ascenso en el escalafón universitario, al establecer el marco categorial de las formas o modalidades de inclusión matricular visibles en la gestión pública oficial ${ }^{6}$, distingue dos tipos de inclusión ${ }^{7}$ que si se toman en consideración se reinterpreta el llamado milagro de inclusión como una sumatoria incapaz de reflejar adecuadamente lo que es Universidad en este país. Dicho de otro modo, refiere a instituciones que nos desarrollan al modo que indica el marco legislativo vigente y con la duración que supone la titularidad universitaria. También lo demuestra con los registros diferenciales de iniciativa oficial y privada, hasta cuando contábamos con la información generada en las Memorias y Cuenta del Ministerio de Universidad, que tiene más vigor el crecimiento de la Privada frente a la oficial. Cuestión que contradice no sólo la discursividad de los Planes de la Patria y la misma Constitución, sino la arquitectura de la gestión y política pública oficial que se describe en La Universidad Venezolana (2013-2019) ${ }^{8}$, donde escrupulosamente se caracteriza el modo en que se desarrolla la intervención del Estado en educación, resaltando la tendencia a monopolizar en manos del Ministerio toda actividad formalmente significativa relacionada con la Universidad. Principalmente en los aspectos curriculares asociados a la definición de carreras por medio de los Planes Nacionales de Formación y la instalación de un tejido institucional típicamente oficial. Todo ello en plano formal, pero en los términos reales que el profesor Rodríguez demuestra con la información oficial disponible, los hechos van por una ruta radicalmente distinta a las declaraciones de las expectativas oficialmente creadas. Tal y como se demuestra con meridiana claridad en los dos cuadros reproducidos a continuación, sobre todo cuando se trata de la inscripción en la Universidad real: 
Cuadro 6. Incremento de la matrícula universitaria regular en carrera (Artículo 109, Constitución de 1999) 1998-2015

\begin{tabular}{|c|c|c|c|c|}
\hline Tipo de iniciativa & 1998 & 2015 & $\begin{array}{c}\mathbf{N} \\
\text { Incremento }\end{array}$ & $\begin{array}{c}\% \\
\text { incremento }\end{array}$ \\
\hline Oficial & 364,100 & 972,245 & 608,145 & $167.0 \%$ \\
\hline Privada & 288,350 & 919,140 & 630,790 & $218.8 \%$ \\
\hline Total & 652,450 & $1,891,385$ & $1,238,935$ & $189.9 \%$ \\
\hline
\end{tabular}

Cuadro 7. Matricula universitaria total en Venezuela*

\begin{tabular}{|c|c|c|}
\hline Oficial & Privada & Total \\
\hline $1,700,877$ & 919,140 & $2,620,017$ \\
\hline $64.92 \%$ & 35.08 & $100 \%$ \\
\hline
\end{tabular}

*Incluye toda forma de estudiante inscrito.

El financiamiento de la educación universitaria según los presupuestos registrados expuestos en las Memorias y Cuenta de los Ministerios del ramo educativo

En ausencia de información válida que pueda sustentar una apreciación comunicable en los términos que rigen este trabajo, pues no se cuenta con las Memorias y Cuenta del Ministerio a partir del 2015, se decidió reproducir el resultado principal de un estudio realizado para el Observatorio de Gasto Público de CEDICE$^{9}$ (Bravo, 2015), el cual demuestra una vez más que una cosa son las palabras, las intenciones, las promesas, las pautas constitucionales, los mandatos de Ley presupuestaria, y otra muy distinta, las realidades que circulan por el año fiscal. Lo decimos por las distancias demostradas, y cada vez más acentuadas, entre la formalidad presupuestaria y el financiamiento real sometido a las carencias de los imprevistos, los déficits estructurales y los caprichos dispendiosos de una gestión y política pública que atiende sin mucho esmero técnico-político los requerimientos financieros de la Universidad.

112 Universidades $\mid$ núm. 83, enero-marzo 2020 | UDUAL $\mid$ DOI: https://doi.org/10.36888/udual.universidades.2020.83.97 Luis Bravo Jáuregui y Ramón Uzcátegui Pacheco | La educación universitaria en Venezuela 201-2019. Aproximación desde el trabajo que se hace en la base de datos de la Línea de Investigación Memoria Educativa Venezolana 
Cuadro 8. Presupuestos sancionados por Ley y presupuestos modificados al 31-12 de cada año fiscal, en bolívares del año 2008

\begin{tabular}{|c|c|c|c|c|c|c|}
\cline { 2 - 7 } & \multicolumn{2}{|c|}{ Ministerio del Poder Popular para la Educación } & \multicolumn{3}{c|}{$\begin{array}{c}\text { Ministerio del Poder Popular } \\
\text { para la Educación Universitaria }\end{array}$} \\
\hline Año fiscal & $\begin{array}{c}\text { 1. Presupuesto } \\
\text { Ley Octubre año } \\
\text { anterior }\end{array}$ & $\begin{array}{c}\text { 2. Presupuesto } \\
\text { ejecutado (incluye } \\
\text { modificación hasta } \\
\text { diciembre) }\end{array}$ & $\begin{array}{c}\text { \% de } \\
\text { variación }\end{array}$ & $\begin{array}{c}\text { 3. Presupuesto } \\
\text { Ley Octubre año } \\
\text { anterior }\end{array}$ & $\begin{array}{c}\text { 4. Presupuesto } \\
\text { ejecutado (incluye } \\
\text { modificación hasta } \\
\text { diciembre) }\end{array}$ & $\begin{array}{c}\text { \% de } \\
\text { variación }\end{array}$ \\
\hline 2004 & $5,801,086,895$ & $7,715,402,132$ & $33.0 \%$ & $3,467,590,649$ & $4,230,921,976$ & $22 \%$ \\
\hline 2005 & $8,172,901,136$ & $9,102,299,945$ & $11.4 \%$ & $5,102,675,221$ & $5,201,355,370$ & $2 \%$ \\
\hline 2006 & $11,794,183,000$ & $14,741,548,771$ & $25.0 \%$ & $6,252,453,879$, & $6,996,603,531$ & $12 \%$ \\
\hline 2007 & $18,593,636,935$ & $19,023,897,292$ & $2.3 \%$ & $9,042,393,473$ & $9,664,102,002$ & $7 \%$ \\
\hline 2008 & $18,331,843,848$ & $19,253,399,882$ & 5.05 & $10,529,222,900$ & $12,880,647,143$ & $22 \%$ \\
\hline 2009 & $20,456,675,987$ & $21,543,864,832$ & $5.3 \%$ & $11,207,034,644$ & $13,539,222,479$ & $21 \%$ \\
\hline 2010 & $23,628,394,139$ & $34,088,412,573$ & $44.3 \%$ & $10,629,294,134$ & $14,837,685,740$ & $40 \%$ \\
\hline 2011 & $26,191,641,547$ & $50,882,932,048$ & $94.3 \%$ & $11,784,526,938$ & $23,304,179,095$ & $98 \%$ \\
\hline 2012 & $33,159,337,814$ & $62,367,157,280$ & $88.1 \%$ & $14,754,515,245$ & $28,179,752,341$ & $91 \%$ \\
\hline 2013 & $41,905,432,769$ & $92,953,558,882$ & $121.8 \%$ & $18,646,214,825$ & $40,361,328,890$ & $116 \%$ \\
\hline 2014 & $55,217,982,107$ & $143,519,674,847$ & $159.9 \%$ & $30,147,100,000$ & $62,813,271,997$ & $108.3 \%$ \\
\hline 2015 & $73,938,741,216$ & $255,770,473,419$ & $246.0 \%$ & $42,360,903,521$ & $167,223,429,011$ & $295.0 \%$ \\
\hline
\end{tabular}

Fuente: Memorias y Cuenta de los Ministerios, tomadas una a una del apartado destinado a la Cuenta, entre el año 2004 y 2015.

Mucho podría decirse de los datos en el cuadro 8, pero lo más notable parece ser el crecimiento sostenido y los enormes aumentos a partir del año 2010 en el MPPE y del 2008 en el MPPEU, posiblemente por efectos de las variaciones inflacionarias más que por las prioridades asumidas para administración de las fianzas del Estado. Pero lo más notable a nuestro ver es la diferencia sugerida entre las asignaciones por ley en octubre de un año y lo que efectivamente se gasta al final del año fiscal siguiente; diferencia que es más importante que otros indicadores de tipo financiero, pues al presentarse de modo tan acentuado, señala claramente la carencia de una racionalidad que permita financiar los requerimientos educativos del país dentro de cierta sensatez u orden fiscal. Lo anterior resalta en el cuadro donde se mide con cierta escrupulosidad las diferencias entre uno y otro renglón de, lo que podría decirse, es la constatación más gruesa de todas las que se han hecho, en tanto que puede ayudar a comprender las diferencias entre lo dicho respecto a la educación y lo que efectivamente se hace en cuanto a la capacidad del ejecutivo para equilibrar presupuestos, en función de los planes de desarrollo que propone. 


\section{Conclusiones}

Todo en este trabajo apunta a la idea de que en 2013 el cambio de actores dentro del ejecutivo nacional, ocurrido a finales del 2012 y a lo largo del 2013, terminó colocando a la universidad venezolana en la misma zona depresiva en que ya estaba el conjunto del sistema educativo escolar. El agravamiento de la depresión económica desatada por efecto del quiebre de la industria petrolera nacional y la ausencia de la fuerza telúrica que le ofrecía el liderazgo al gobierno desde 1999, hizo naufragar el modelo educativo según el cual la educación universitaria era la prioridad real del proyecto político instalado desde 1999.

De ese modo y luego de haber hecho lo expuesto, más allá de los límites impuestos por la ausencia de la información contenida en las Memorias y Cuenta del Ministerio de Universidad desde el 2015, suponemos haber probado que a partir de 2013 se agudizó la indiferencia oficial por las pautas de la Constitución de 2019, hasta un punto en que es posible apreciar una dinámica en ella que atiende más a las necesidad de afirmación en el poder de la hegemonía impuesta en el 2012 durante la enfermedad del presidente Chávez; a partir de esas fechas la Educación Universitaria empieza a mostrar un desarrollo tan recesivo como el resto del sistema, desde el año 2007, en materia de dinámica matricular respecto a la dinámica poblacional. Conclusión sumaria que se construye por vías de un relato descriptivo-analítico metódicamente orientado por el contraste entre lo que define el 109 de la Constitución Nacional y la dinámica matricular y financiera que se describe en los informes anuales de seguimiento producidos en la Línea de Investigación Memoria Educativa Venezolana (Bravo, 2019-A), en crítica correspondencia con el trabajo de investigación que producen Ruth Galaviz (2019-A y B) y Robert Rodríguez (2019).

De este modo esperamos haber contribuido a la caracterización del componente Universitario del Sistema Educativo Escolar Venezolano, a pesar de que reconocemos su parcialidad, por quedar fuera del esfuerzo de investigación aspectos clave de la universidad venezolana como son la investigación y la extensión. Para quien tenga especial interés en esos aspectos no trabajados aquí, puede acceder a la Sala de Lectura EUDAIMONíA de la LIMEV en BOX https://app.box.com/s/zkfnq0naobw0i8co2rs8qj2b0dd3wze9 y al Centro de Investigaciones de la Escuela y Educación (CENDOC-CIES) https://ucv.cies.cendoc de manera gratuita. 
1. Una descripción intensiva del origen, desarrollo y resultados de esta opción académica para el estudio ordenado del sistema educativo escolar venezolano puede consultarse en: https://app.box. $\mathrm{com} / \mathrm{s} / \mathrm{sagu} 4 \mathrm{qom} 1$ of3txn9kyy7gs8rkfrl7exj; ahí se encuentran los informes anuales presentados a las autoridades de la universidad como testimonio de nuestra labor para estudiar sistemáticamente el acontecer educativo. A su vez este documento sirve de vitrina exterior de la Sala de Lectura EUDAIMONÍA, que reúne y hace pública la producción histórica fundamental de la Línea; el acervo está disponible en https://app.box.com/s/zkfnq0naobw0i8co2rs8qj2b0dd3wze9 de manera gratuita.

2. Los instrumentos jurídicos vigentes que norman la universidad venezolana actualmente son: Constitución de la República Bolivariana de Venezuela (1999); Ley de Universidades 1970; Ley Orgánica de Educación 2009; los reglamentos generales de cada universidad, sancionados por los respectivos Consejos Universitarios en uso de la Autonomía Universitaria, ratificada por la CRBV; decretos gubernamentales como Alma Máter mediante el Decreto 6.650 del 24 de marzo de 2009, publicado en Gaceta Oficial Nº 39.148 del 27 de marzo 2009; y la reglamentación interna de la universidades.

3. Documento presentado para la discusión, no disponible en línea. Las personas que deseen acceder al documento completo, solicitarlo a la siguiente dirección de correo electrónico: rthugalaviz@gmail.com (Galaviz, 2019).

4. El blog se ha convertido en la principal fuente de información respecto a las intenciones formales de política pública que orientan al Ministerio del Poder Popular para la Educación Universitaria (MPPEU), en ausencia de la tradicional página web (a esta fecha), y las Memorias y Cuenta, tal cual puede verse por: https://temaseducacionuniversitaria.blogspot.com/2019/08/ la-politica-de-territorializacion-en-el.html? $\mathrm{m}=1$ de manera gratuita.

5. Creación de los Programas Nacionales de Formación (PNF). 2008: correspondientes al nivel de pregrado, administrados en todo el territorio nacional, vinculándose durante todo el proceso formativo con las comunidades y el ejercicio profesional, a partir de las necesidades y características de las localidades. Hasta la fecha se han creado 78 PNF en diferentes áreas de conocimiento.

Creación de la Misión Alma Mater. 2009: dirigida, entre otros aspectos, hacia el establecimiento de la educación superior a nivel nacional, en estrecho vínculo con las comunidades para el logro de la soberanía política, tecnológica, económica, social y cultural.

Creación de las Universidades Politécnicas Territoriales (UPT). 2010: abarcan múltiples campos de estudio y abordan las necesidades de su contexto territorial "( ) a partir de las realidades geo-históricas, culturales, sociales y productivas”, para así conformar una nueva geopolítica nacional. Las UPT corresponden a los alcances de la Misión Alma Mater y su proceso de creación culminó en el año 2018. Hasta la fecha se han creado 26 UPT en todo el territorio nacional. Comité para el Direccionamiento Estratégico de la Misión Sucre y la Misión Alma Mater. 2011. Comité para la Territorialización de la Gestión del Ministerio del Poder Popular para la Educación Universitaria. 2011.

Comité para el Desarrollo del Componente de Innovación Socioproductiva de la Educación Universitaria. 2011.

Subcomités Territoriales de Educación Universitaria. 2011.

Creación de los Programas Nacionales de Formación Avanzada (PNFA).

Comisionado Territorial de Educación Universitaria. 2013.

Creación de la Universidades Territoriales. 2014: corresponden a los alcances de la Misión Alma Mater.

6. “Tal política de inclusión masiva derivó en un conjunto de iniciativas enfocadas en incrementar el acceso y la matrícula universitaria, a lo largo de todos estos años, entre las que se pueden mencionar: (a) creación de universidades, (b) transformación de instituciones existentes, (c) creación de la llamada Misión Sucre en el año 2003 y finalmente (d) la Misión Alma Mater (2009) que sintetiza la política universitaria de la autodenominada Revolución Bolivariana, las misiones se institucionalizan fuera del marco constitucional como ejemplo de consolidación de un modelo para definir jurídicamente y operacionalizar las políticas sociales, según (Gaceta Oficial $N^{\circ} 6.217,2008$ ), igualmente con el imperativo de democratizar el acceso a la universidad" (Rodríguez, Robert, 2018). 
7. Para efectos de las IEU (Instituciones de Educación Superior) en Venezuela existen actualmente dos tipos de matrícula, según se desprende en cada una de las Memorias y Cuentas presentadas a partir del 2005 al 2015 -cuando se entregó la última conocida oficialmente- (MPPEUCT, 2016): una denominada "estudiantes en carrera" y otra "estudiantes o matrícula PNF (Programas Nacionales de Formación)". Esta distinción que claramente procura saldar jurídicamente la responsabilidad administrativa ante la LEU vigente aclara que la matrícula PNF no es regular según los requisitos de la LEU. Valga puntualizar que las universidades privadas no administran PNF, por lo tanto, declaran toda su matrícula como estudiantes en carrera. En los últimos años los programas denominados PNF instaurados según Resolución 2,963 de fecha 13 de mayo de 2008, publicada en Gaceta Oficial 38.930 del 14 de mayo de 2008, se han impuesto y masificado como fórmula paralela a los programas regulares de estudio que están dentro del ordenamiento jurídico vigente, según revela el informe oficial de la Misión Alma Máter (2010). En este mismo se puede leer que la Misión Sucre (2003), creada para incluir masiva y aceleradamente estudiantes universitarios en los denominados PNF en cada municipio o localidad, llevó a cabo sus objetivos al unificarse como mecanismo paralelo a la institucionalidad legal vigente; dicha puntualización conceptual es necesaria para poder entender lo que es y no es considerado matrícula desde el punto de vista jurídico, pedagógico y efectivo.

8. Disponible para su consulta en: https://app.box.com/s/c327uf9p905sci36eu8miurhznd9k514

9. "El Observatorio de Gasto Público de CEDICE Libertad, tiene el placer de compartir este trabajo del profesor Luis Bravo Jáuregui, en el cual se plantea un estudio exploratorio para instalar un observatorio sobre el gasto social en Venezuela. Sus resultados más importantes remiten a la posibilidad de contar con un conjunto de cuadros y referencias que permiten año a año y de modo sistemático alimentar una percepción lúcida sobre el estado de la cuestión, a partir de una imagen de arranque que muestra las distancias significativas entre lo que dice el discurso oficial sobre la generosidad del financiamiento educativo y las realidades que se representan en las estadísticas más confiables que lo identifican." El financiamiento educativo y social en Venezuela, disponible para su consulta en https://cedice.org.ve/observatoriogp/portfolio-items/ investigacion-3-el-financiamiento-educativo-y-social-en-venezuela/ de manera gratuita.

* La universidad venezolana de 1999 en adelante: un análisis de las referencias a Universidad presentes en la Base de Datos de la Línea de Investigación Memoria Educativa Venezolana, puede ser consultado libremente en: https://app.box.com/s/x3vtssfug12mimnl5jth4qn4sd48yp7n

** Disponible para consulta en https://app.box.com/s/bgw0vrbvf2eb1dp2qlxvbz8i8oqfba9q

*** “En estos 6 años vamos a alcanzar el 100\% de escolaridad.” El presidente de la República Bolivariana de Venezuela, Nicolás Maduro, destacó este martes que durante el período de gobierno 2019-2025 se buscará alcanzar el 100\% de la escolaridad hasta la Universidad. "Venezuela le garantiza, y yo como Presidente Constitucional legítimo les garantizo en este período 20192025 que vamos a llegar en este período de 6 años, más temprano que tarde, vamos a lograr el $100 \%$ de escolaridad de todos los niños, jóvenes y pueblo venezolano en la educación gratuita. pública y de calidad", dijo en el acto de graduación de 692 profesionales en la docencia de la Micro Misión Sucre, desde el Teatro de la Academia Militar, Caracas ( ). Prensa Miraflores. AVN. http://www.avn.info.ve/contenido/belkis-bigott-nueva-rectora-universidad-nacional-experimental-del-magisterio 17-01-2019

Promoción Comandante Eterno "Hugo Chávez Frías". Efectuado en el Acto de Grado Cohorte 2017-2 de la UBV y Misión Sucre. (...) Más de 500 mil egresados en 15 años gracias a la Revolución. MUSTARIZ Prensa MPPEUCT/UT Carabobo/Carlos Romero. https://www.mppeuct.gob. ve/actualidad/noticias/efectuado-acto-de-grado-cohorte-2017-2-de-la-ubv-y-mision-sucre. 10 de diciembre de 2018.

${ }^{* * * *}$ El jefe de Estado participa en Rusia en la VI Cumbre Mundial de la Energía. Durante su participación en la Vi Cumbre Mundial de la Energía, que se celebra en Moscú, Rusia, el presidente de la República, Nicolás Maduro, destaca este miércoles que Venezuela tiene la matrícula universitaria más alta en Latinoamérica, después de Cuba.

Desde la llegada de la revolución bolivariana, Venezuela ha incrementado su matrícula universitaria de 700 mil, en 1998, a más de 3 millones de estudiantes en la actualidad, con la creación de la Misión Sucre, nuevas casas de saberes y las Universidades Politécnicas Territoriales, además de la democratización del Sistema Nacional de Ingreso.

Según cifras avaladas por la Organización de las Naciones Unidas para la Educación, la Ciencia y la Cultura (UNESCO), Venezuela ocupa el quinto lugar en tasa de matrícula universitaria

116 Universidades $\mid$ núm. 83, enero-marzo 2020| UDUAL | DOI: https://doi.org/10.36888/udual.universidades.2020.83.97 Luis Bravo Jáuregui y Ramón Uzcátegui Pacheco | La educación universitaria en Venezuela 201-2019. Aproximación desde el trabajo que se hace en la base de datos de la Línea de Investigación Memoria Educativa Venezolana 
en el mundo, superando incluso a naciones como Estados Unidos, Francia y España. Entre las naciones de América Latina, nuestro país se encuentra en la segunda posición, superada sólo por Cuba. Prensa Mppeuct / Joselin Jiménez. Publicado el 4 de octubre de 2017. https://www. mppeuct.gob.ve/actualidad/noticias/maduro-venezuela-tiene-la-segunda-matricula-mas-alta-de-latinoamerica 11-10-2017. Consultado en 2018.

\section{Referencias}

Arias Alfonzo, D.; Maduro, N. (2019). Análisis del Informe a la nación presentado por el Presidente Nicolas Maduro en Cadena Nacional de Radio y Televisión. Viernes 01 de septiembre 2019.

Asamblea Nacional Constituyente (1999). Constitución de la República Bolivariana de Venezuela. Gaceta Oficial de la República Bolivariana de Venezuela, 5.453 (Extraordinario), marzo 24, 2000.

Asamblea Nacional Constituyente (2019). Proyecto Nacional Simón Bolívar, Tercer Plan Socialista de Desarrollo Económico y Social de la nación, 2019-2025. Gaceta Oficial de la República Bolivariana de Venezuela, 6.446 (Extraordinario), abril 08 de 2019.

Asamblea Nacional (2009). Ley Orgánica de Educación. Gaceta Oficial de la República Bolivariana de Venezuela, 5.929 (Extraordinario), agosto 15 de 2009.

Bravo Jáuregui, L. (2015). El financiamiento educativo. Gasto (inversión) social en Venezuela. Observatorio del gasto público. CEDICE. Caracas. https://cedice.org.ve/observatoriogp/portfolio-items/investigacion-3-el-financiamiento-educativo-y-social-en-venezuela/

Bravo Jáuregui, L.; Uzcátegui Pacheco, R. (2019). Anuario de la Línea de Investigación Memoria Educativa Venezolana. https://app.box.com/s/sagu4qom1of3txn9kyy7gs8rkfrl7exj

Bravo Jáuregui, L.; Uzcátegui Pacheco, R.; Chacón, C.E. (2019). Informe 2019. Seguimiento del Sistema Educativo Escolar Venezolano. Línea de Investigación Memoria Educativa Venezolana CIES-Escuela de Educación-FHyE-UCV. https://app.box.com/s/fxyc616uoqteti0ifca69id3rk06sic5

Congreso de la República de Venezuela. Ley de universidades. Gaceta Oficial Nº 1.429 http://www. ucv.ve/fileadmin/user_upload/comision_electoral/Normativa_legal/index.htm (Extraordinaria), septiembre 08 de 1970.

CONATEL (2013). Ley del Plan de la Patria 2013-2019. Segundo Plan Socialista De Desarrollo Económico Social de la Nación 2013-2019. Publicado en Gaceta Oficial de la República Bolivariana de Venezuela No 6.118 Extraordinario, 04 de diciembre de 2013 http://www.conatel.gob.ve/ ley-del-plan-de-la-patria-2013-2019/ Consultada el 06 de septiembre 2019.

Galaviz, R. (2019-A). El Sistema de Educación Universitaria Venezolano de cara al Plan de la Patria. https://temaseducacionuniversitaria.blogspot.com/2019/08/el-sistema-de-educacion-universitaria.html, agosto 03 de 2019.

Galaviz, Ruth (2019-B). El Sistema de Educación Universitaria Venezolano de cara al Plan de la Patria. https://temaseducacionuniversitaria.blogspot.com/2019/08/el-sistema-de-educacion-universitaria.html, agosto 03 de 2019.

Observatorio Regional de Planificación para el Desarrollo de América Latina y el Caribe (2014). Plan de la Patria 2013-2019 de Venezuela. https://observatorioplanificacion.cepal.org/es/ planes/plan-de-la-patria-2013-2019-de-venezuela Consultado el 06 de septiembre de 2019

Rodríguez, R. A. (2018). Venezuela: ¿potencia universitaria? La Posverdad oficialista de la Inclusión Universitaria 1998-2015. Trabajo presentado como requisito para ascenso a la categoría de profesor Agregado. UPEL-IPC, Caracas, julio de 2018.

Uzcátegui, R. y Bravo Jáuregui, L. (2015). Les universités latino-américaines aujourd'hui: expressions locales. DIRE $\mathrm{n}^{\circ} 7 \mid 2015$ http://epublications.unilim.fr/revues/dire - ISSN: 2260-1155 